\title{
Giant Thyroid Mass Excision Using Energy Device and Pectoralis Major Myocutaneous Flap Reconstruction
}

\author{
Min Seok Song \\ Sang Joon Lee \\ Seung Hoon Woo
}

Department of Otorhinolaryngology-Head and Neck Surgery, Dankook University College of Medicine, Cheonan, Korea

\section{Correspondence}

Seung Hoon Woo

Department of Otorhinolaryngology-Head and Neck Surgery, Dankook University College of Medicine, 119 Dandae-ro, Dongnam-gu,

Cheonan 31116, Korea

Tel.: +82-41-550-1781

Fax: +82-41-550-7837

E-mail: lesabydahanmail.net

(C) Korean Society for Laser Medicine and Surgery

(@) This is an open access article distributed under the terms of the Creative Commons Attribution NonCommercial License (http://creativecommons.org/ licenses/by-nc/4.0) which permits unrestricted noncommercial use, distribution, and reproduction in any medium, provided the original work is properly cited.

\begin{abstract}
A giant thyroid mass can be associated with severe compressive symptoms, requiring surgery for treatment. This paper reports the case of an 82-year-old man who presented with a giant thyroid mass that was suspected of being a metastatic papillary thyroid carcinoma on fineneedle aspiration cytology. A harmonic scalpel was used to excise the giant thyroid mass. A pectoralis major myocutaneous flap was used for reconstruction. The histopathology assessment confirmed the metastases in the lymph node and papillary thyroid carcinoma in the resected gland.
\end{abstract}

\section{Key words}

Papillary thyroid cancer; Energy device; Pectoralis major myocutaneous flap 


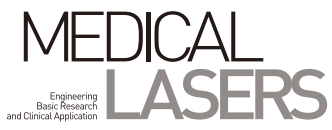

\section{INTRODUCTION}

Papillary thyroid cancer usually presents as a palpable thyroid mass that could be associated with pain, hoarseness, stridor, or dysphagia. In rare cases, it presents solely as cervical lymphadenopathy with an otherwise grossly normal thyroid gland.'

A giant thyroid tumor is defined as any thyroid tumor with an average weight $>500 \mathrm{~g}$ and diameter $>100 \mathrm{~mm}$, wherein the upper end extends up to the mandibular angle, the lower end extends to the sternum, and both sides of the posterior border are normally sternocleidomastoid (SCM) muscle. ${ }^{2}$

The present case was that of an 82-year-old man who was admitted with swelling in the left neck that progressively grew in 4 months and finally ruptured. Following a series of work up that included fine needle aspiration (FNA), computed tomography (CT) scan, and positron emission tomography-CT, the thyroid mass was proven to be metastatic papillary cancer. We performed total thyroidectomy, radical neck dissection, and reconstruction with PMMC flap. ${ }^{3}$

\section{CASE REPORT}

An 82-year-old man presented with swelling in the left neck that was progressively increasing in size for 4 months (Fig. 1). He did not complain of dysphagia, dyspnea, hoarseness, hematemesis, or stridor. Physical examination showed a firm, hard, well-defined mass measuring $7 \mathrm{~cm} \times 6 \mathrm{~cm} \times 6 \mathrm{~cm}$. Fine needle aspiration of the mass revealed metastatic papillary carcinoma.

Contrast-enhanced CT of the neck revealed a $7.7 \mathrm{~cm}$ $\times 6.2 \mathrm{~cm} \times 6.3 \mathrm{~cm}$ heterogeneous enhancing mass, left neck level III and IV (Fig. 2). The mass was engulfing the left internal jugular vein and invading the left SCM muscle and the overlying skin. Furthermore, multiple variablesized lymph nodes were identified in the left neck level I-IV.

The patient underwent a total thyroidectomy and left radical neck dissection with a harmonic scalpel (Fig. 3) that cuts the tissues through vibration and ligates the blood vessel. This method was used because it does not involve the flow of electricity into the body and does not stimulate the muscles through electric current flow. ${ }^{4}$ With the use of this principle, safe use has been reported, even around the recurrent laryngeal nerve during endoscopic thyroid surgery. ${ }^{5}$ In this case, ETHICON GEN11 Generator and HARMONIC FOCUS + Shears (Johnson \& Johnson

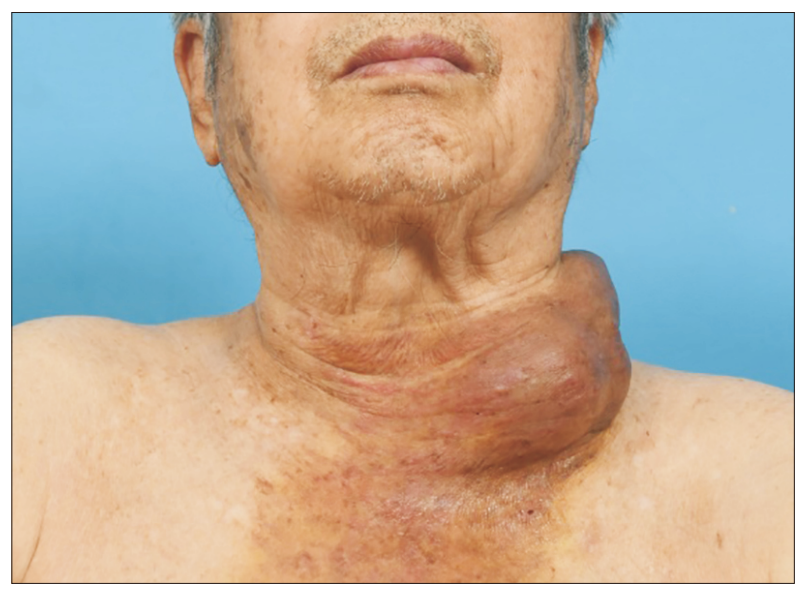

Fig. 1. An isolated left neck enlargement with no apparent thyroid swelling.
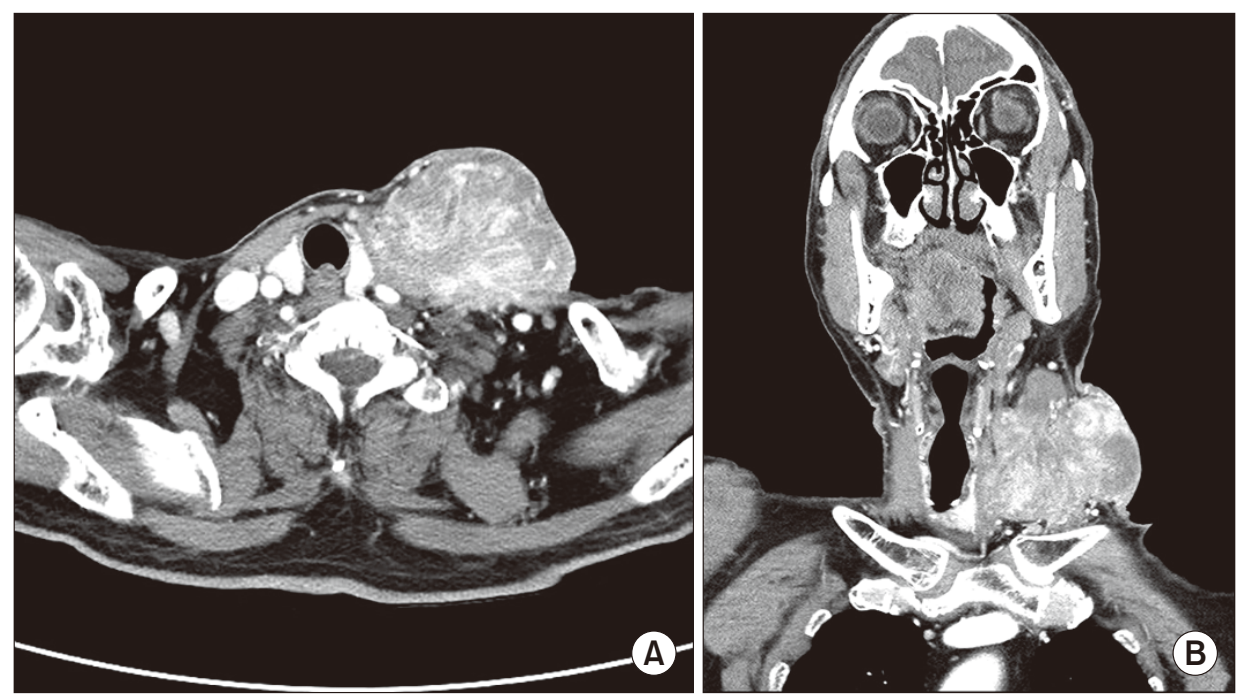

Fig. 2. (A) Axial view of computed tomography (CT) scan showing a heterogeneous mass at left Anterior neck, involving skin. (B) Coronal view of CT scan showing a same mass. 

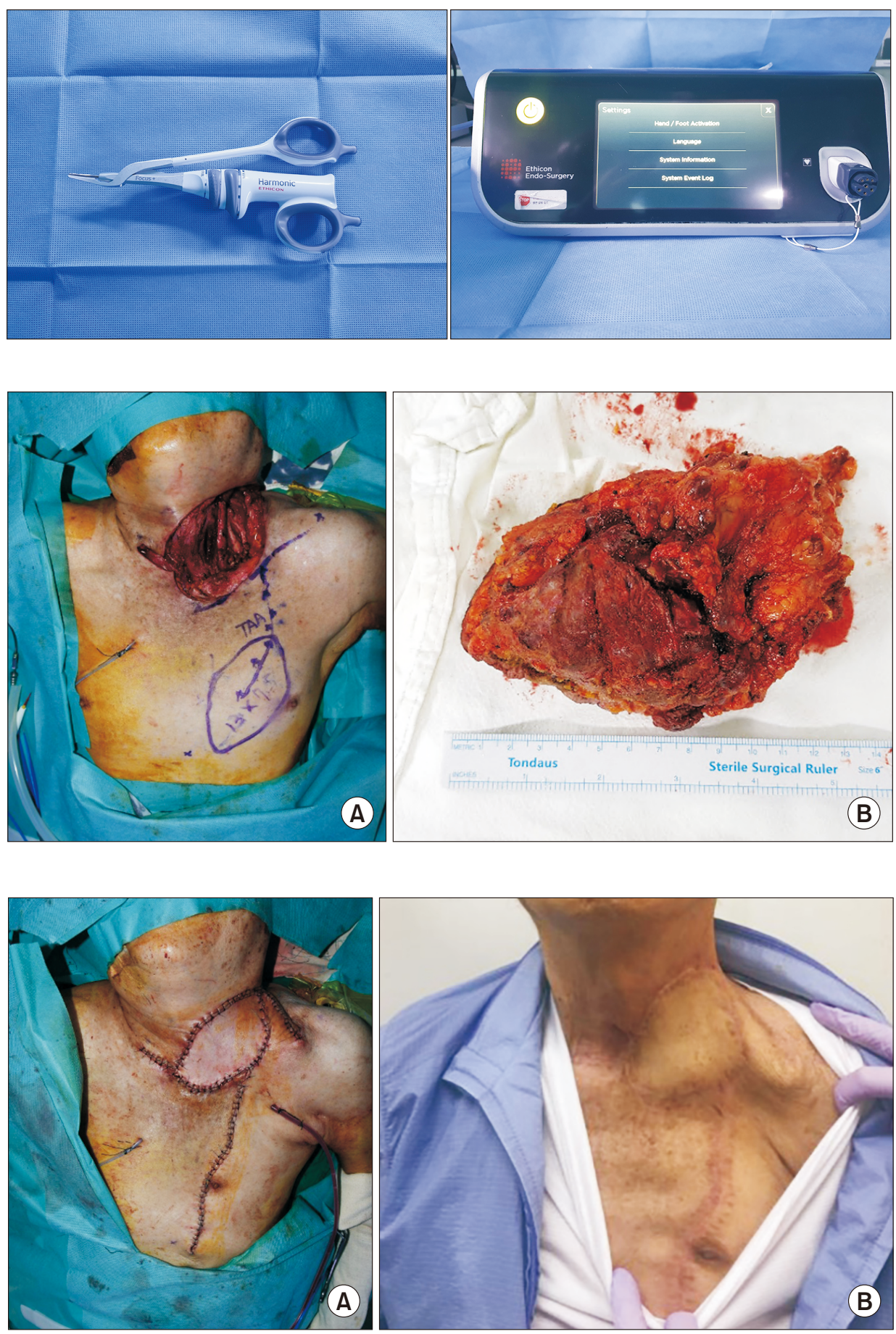

Fig. 3. Harmonic scalpel used in this case.

Fig. 4. (A) An intra-operative picture A. Showing total thyroidectomy radical neck dissection. (B) Showing a huge mass sized about $13.0 \mathrm{~cm} \times$ $7.7 \mathrm{~cm}$.
Fig. 5. (A) An Intraoperative image after pectoralis major myocutaneous (PMMC) flap. (B) Post-operative image of PMMC flap.
Medical Devices Companies, New Jersey, USA) were used.

An incision was made 2 fingers above the sternal notch, and the tumor was dissected carefully to reserve both the parathyroid glands and clearly identify the recurrent laryngeal nerve. Total thyroidectomy and en-bloc resection of the mass were performed. Multiple enlarged left level II to IV, VI nodes were also removed (Fig. 4). Thereafter, reconstruction was performed with a pectoralis major myocutaneous flap sized about $13 \mathrm{~cm} \times 7.5 \mathrm{~cm}$ (Fig. 5A). ${ }^{6}$

Histopathological examination revealed a $0.8 \mathrm{~cm} \times 0.4$ $\mathrm{cm}$ in left lobe and $0.4 \mathrm{~cm} \times 0.3 \mathrm{~cm}$ in the right lobe of papillary thyroid cancer (PTC) from the excised gland with nuclear features consistent with papillary thyroid carcinoma and a metastatic lymph node.

The patient exhibited good postoperative recovery and 
was discharged. Levothyroxine was administered for thyroid function replacement (Fig. 5B).

\section{DISCUSSION}

Ultrasonography is the current choice of imaging modality for screening and evaluation of cervical lymph node (LN) metastases in thyroid cancer. Several sonographic criteria, such as loss of fatty hilum, hyper-echogenicity, round shape, calcification, and cystic change, have been used for diagnosing metastatic LNs. ${ }^{7}$

Papillary thyroid cancer, the most common thyroid malignancy, is associated with cervical lymph node metastases in 30\%-90\% of the patients. Although PTC has an excellent prognosis, lymphatic spread is associated with an increased risk of loco-regional recurrence that significantly impairs the life quality and can alter patient prognosis. $^{8}$

While surgery is the primary treatment modality for PTC, radioactive iodine and thyroid hormone suppression are commonly used as complementary treatments. Although thyroid hormone suppression may lower the recurrence rate, and radioactive iodine may aid the diagnosis and treatment of metastases, lymph node dissection is the mainstay treatment for clinically evident cervical lymph node metastases. ${ }^{\text {. }}$

The potential complications caused by cervical lymph node dissections are mainly hypoparathyroidism Itemporary or permanent) and nerve injury involving; recurrent laryngeal nerve, superior laryngeal nerve, spinal accessory, and phrenic nerves; the brachial and cutaneous cervical plexus; and the sympathetic chain. Other complications include chyle leakage, hemorrhage, seroma, and wound infection. ${ }^{10}$

Nevertheless, neck dissection improved the outcome in some subsets of patients with PTC particularly in patients wherein gross nodal metastasis was noticed before or during the surgery, those in whom the primary tumor invaded beyond the thyroid capsule, and female patients older than 60 years old. ${ }^{11}$

Energy devices, such as harmonic scalpel, are widely used in the field of otorhinolaryngology. It operates at a lower temperature $\left(50^{\circ} \mathrm{C}-100^{\circ} \mathrm{C}\right)$ than other devices that are generally used at $150^{\circ} \mathrm{C}-400^{\circ} \mathrm{C}$ to minimize tissue damage ${ }^{12}$ Unlike other instruments, scalpel cuts the tissue with the heat generated using vibration instead of electricity; therefore, it is used without muscle contraction. ${ }^{13-15}$

Harmonic scalpel also has some positive reports that suggest that it achieves better results in term of less postoperative pain complains by patients. Further, it involves a shorter total operative time, low intraoperative blood loss, and low postoperative pain, with no increase in surgical difficulty. 16,17

\section{CONFLICT OF INTEREST}

Seung Hoon Woo is the Editor-in-Chief of the journal but was not involved in the review process of this manuscript. Otherwise, there is no conflict of interest to declare.

\section{FUNDING}

None.

\section{REFERENCES}

1. Machado NO, Chopra PJ, Al Hamdani A. Papillary carcinoma of the thyroid presenting primarily as cervical lymphadenopathy: an approach to management. Sultan Qaboos Univ Med J 2009;9:328-32.

2. Du W, Liu ST, Li P, Sun LY, Zhao M, Qi JX, et al. Intra- and postoperative complications in 137 cases of giant thyroid gland tumor. Oncol Lett 2012;4:965-9.

3. Tripathi M, Parshad S, Karwasra RK, Singh V. Pectoralis major myocutaneous flap in head and neck reconstruction: an experience in 100 consecutive cases. Natl J Maxillofac Surg 2015;6:37-41.

4. Cho SB, Kim HS. High-frequency alternating electrical current: selective electromagnetic tissue reaction. Med Lasers 2016:5:1-6.

5. Siperstein AE, Berber E, Morkoyun E. The use of the harmonic scalpel vs conventional knot tying for vessel ligation in thyroid surgery. Arch Surg 2002;137:137-42.

6. Lee SJ, Park ES. Enhancement of contour using laser scar treatment in the one-stage nasal ala reconstruction with nasolabial fold flap. Med Lasers 2018;7:41-6.

7. Stulak JM, Grant CS, Farley DR, Thompson GB, van Heerden $J A$, Hay ID, et al. Value of preoperative ultrasonography in the surgical management of initial and reoperative papillary thyroid cancer. Arch Surg 2006;141:489-94.

8. Caron NR, Clark OH. Papillary thyroid cancer: surgical management of lymph node metastases. Curr Treat Options Oncol 2005;6:311-22.

9. Sakorafas GH, Sampanis D, Safioleas M. Cervical lymph node dissection in papillary thyroid cancer: current trends, persisting controversies, and unclarified uncertainties. Surg Oncol 2010;19:e57-70.

10. El-Foll HA, El-Sebaey H, El-Kased A, Hendawy A, Kamel M. Pattern and distribution of lymph node metastases in papillary thyroid cancer. J Clin Exp Pathol 2015;5:204. 
11. Noguchi S, Murakami N, Yamashita H, Toda M, Kawamoto H. Papillary thyroid carcinoma: modified radical neck dissection improves prognosis. Arch Surg 1998;133:276-80.

12. Kwon TR, Lee SE, Kim JH, Jeon YJ, Jang YN, Yoo KH, et al. The effectiveness of $448-\mathrm{kHz}$ capacitive resistive monopolar radiofrequency for subcutaneous fat reduction in a porcine model. Med Lasers 2019;8:64-73.

13. Milsom J, Trencheva K, Monette S, Pavoor R, Shukla P, Ma J, et al. Evaluation of the safety, efficacy, and versatility of a new surgical energy device (THUNDERBEAT) in comparison with Harmonic ACE, LigaSure V, and EnSeal devices in a porcine model. J Laparoendosc Adv Surg Tech A 2012;22:378-86.

14. Im NR, Moon J, Choi W, Kim B, Lee JJ, Kim H, et al. Histologic evaluation of blood vessels sealed with 1,470-nm diode laser: determination of adequate condition for laser vessel sealing. Med Lasers 2018;7:6-12.
15. Cho Hi, Won $\mathrm{CH}$, Chang SE, Lee MW, Park GH. Usefulness and limitations of skin explants to assess laser treatment. Med Lasers 2013;2:58-63.

16. Litta P, Fantinato S, Calonaci F, Cosmi E, Filippeschi M, Zerbetto $\mathrm{I}$, et al. A randomized controlled study comparing harmonic versus electrosurgery in laparoscopic myomectomy. Fertil Steril 2010;94:1882-6.

17. Koh YW, Lee SW, Shin JM, Park JH, Lee JD, Kim KH, et al. Efficacy of the harmonic scalpel in parotidectomy. Korean J Otorhinolaryngol-Head Neck Surg 2006;49:313-8.

How to cite this article: Song MS, Lee SJ, Woo SH. Giant thyroid mass excision using energy device and pectoralis major myocutaneous flap reconstruction. Med Lasers 2021; 10:115-119. https://doi.org/10.25289/ML.2021.10.2.115 